\title{
Situación de violencia contra los defensores de derechos humanos en Colombia despues del acuerdo de paz
}

\section{Violence situation against human rights defenders in Colombia after the peace agreement}

\author{
DOI: https://doi.org/10.17981/juridcuc.15.1.2019.08
}

Artículo de reflexión. Fecha de Recepción: 02/04/2019 Fecha de Aceptación: 07/08/2019

\author{
Camila Villamizar-Acosta \\ Universidad del Magdalena, Santa Marta (Colombia) \\ villamizarac276@gmail.com
}

Para citar este artículo:

Villamizar-Acosta, C. (2019). Situación de violencia contra los defensores de derechos humanos en Colombia despues del acuerdo de paz. JURÍDICAS CUC, 15(1). 209-228. DOI: http://dx.doi. org/10.17981/juridcuc.15.1.2019.08

Resumen

El presente artículo hace una reflexión sobre la situación de violencia que viven los defensores de derechos humanos en Colombia, y tiene por objetivo evidenciar como después del Acuerdo de paz se ha incrementado el número de homicidios de sus integrantes, cuya sistematicidad ha sido negada por varias instituciones del gobierno nacional, dificultando el desarrollo de programas de protección; generando preguntas sobre quien defiende a los defensores. Desde el plano metodológico se realizó una investigación documental, para lo cual se analizaron informes de diversas índoles permitiendo comprender el fenómeno a estudio. Como conclusión se plantea la necesidad de ir más allá de las expresiones de apoyo, no dejar en manos de los defensores su seguridad y pedir mayor compromiso por parte del gobierno en la protección de los defensores, sin olvidar que la mejor estrategia sería la implementación del acuerdo de paz.

Palabras clave: Acuerdo de paz; defensores de derechos humanos; homicidios; protección; sistematicidad; violencia.

\section{Abstract}

This article reflects on the situation of violence experienced by human rights defenders in Colombia, and aims to show how, after the peace agreement, the number of homicides of its members has increased, whose systematicity has been denied by several national government institutions, making it difficult to develop protection programs, generating questions about who defends the defenders. From the methodological point of view, a documentary investigation was carried out, for which various types of reports were analyzed, allowing us to understand the phenomenon under study. As a conclusion, it is necessary to go beyond expressions of support, not to leave their security in the hands of defenders and to ask for greater commitment on the part of the government in the protection of defenders, without forgetting that the best strategy would be the implementation of the peace agreement.

Keywords: Homicide; human rights defenders; peace agreements; protection; systematicity; violence. 


\section{INTRODUCCIÓN}

A pesar de la constante violación de los derechos humanos durante gran parte de la historia colombiana, el presente artículo se circunscribe a lo relacionado con la lucha por el poder político y específicamente a lo acaecido después de la implementación del Acuerdo de paz, firmado entre el Gobierno Nacional y las Fuerzas Armadas Revolucionarias de Colombia (FARC).

En cuanto a la violación de los derechos humanos y el derecho internacional humanitario, todavía resuena el eco por los acontecimientos producidos en la llamada "Violencia", período caracterizado por el enfrentamiento fratricida entre dos grupos, diferenciados por la bandera de un partido, podía ser el liberal o el conservador. Esta lucha desencadenada durante el cuatrienio del gobierno de Ospina Pérez (1946-1950) y que terminó en 1965. Las razones de los combatientes era defender su partido de las ambiciones de sus contradictores (Rehm, 2014).

Durante este enfrentamiento partidista apareció el germen de la después llamada FARC. Hacia los años 80, en medio de la con ación guerrilla-fuerzas armadas, surgen los grupos paramilitares patrocinados por narcotraficantes, produciéndose una degradación de la guerra.

Los enfrentamientos Estado-Paramilitares-Guerrilla dejaron aproximadamente 220.000 muertos, 8 millones de víctimas, 7 millones de desplazados, generaron grandes pérdidas económicas y amplias zonas del campo quedaron infectadas con minas “quiebra patas". Según el informe ¡Basta Yai, elaborado por el Centro de Memoria Histórica (2013):

Se trata de cientos de miles de víctimas fatales producto en especial de masacres, y asesinatos selectivos, a las que hay que sumar, muchos otros miles de víctimas de desaparición forzada, desplazamiento forzoso, secuestros, ejecuciones extrajudiciales, reclutamiento ilícito, tortura y sevicia, minas antipersonales, y violencia sexual (p. 12). 
A raíz de esta situación y con el fin de terminar "EL conflicto", el gobierno del Presidente Santos, decidió en el año 2010 iniciar conversaciones de paz con la FARC, las cuales concluyeron en el 2016 con la firma del Acuerdo General para la Terminación del Conflicto y la Construcción de una Paz Estable y Duradera. La implementación de dicho acuerdo produjo una disminución en el número de homicidios por motivos políticos, pero desafortunadamente se incrementó el de los defensores de los derechos humanos (Front Line Defenders, 2018).

Estos hechos han llevado a diferentes organismos e instituciones, no solo a denunciar sino a investigar sobre las posibles causas y la sistematicidad de los homicidios, cuyas conclusiones no han sido aceptadas por instituciones oficiales, quienes las niegan, dificultando la realización de estrategias de protección de los defensores, situación que lleva a preguntarse sobre cómo defenderlos de agresiones letales.

Incluso, como en otros asuntos de indefensión humana, tal como lo expresa Gutiérrez (2014), pueda evaluarse una estructura jurídica que en el extremo responda con cada articulado y marco legislativo, frente a los planteamientos reportados por un tema como este, las problemáticas centrales junto con sus consecuencias deben pasar a estudio y revisión permanente por diferentes estamentos.

Los datos de investigaciones sirvieron de insumo para la elaboración de esta reflexión y permitieron dar cuenta de las zonas y motivos para los homicidios y como la desprotección del Estado llevó a los mismos defensores a diseñar estrategias para defender su vida y a considerar necesaria la implementación del Acuerdo de Paz.

\section{Discusión}

Por defensor de derechos humanos se asume "una persona que trabaja para promover o proteger los derechos humanos con métodos no violentos" (Human Rights First, 2009, p. 7). La 
Oficina del Alto Comisionado para los Derechos Humanos de las Naciones Unidas (OACNUDH, 2004) los describe como la "persona que, individualmente o junto con otras, se esfuerza en promover o proteger esos derechos" (p. 3). La situación de los defensores en el mundo, es bastante difícil:

... se enfrentan a una gran cantidad de obstáculos en su labor, los cuales incluyen desde aquellos ataques más severos en contra de su vida e integridad personal, como los asesinatos y desapariciones forzadas, hasta aquellos dirigidos a limitar el ejercicio de sus funciones (Encinas, 2018 p. 14).

En Colombia el nivel de dificultad es mayor, tanto es así que Amnistía Internacional (2017), lo considera uno de los países más letales para los miembros de estos grupos. Entre las razones por los cuales los defensores son atacados se encuentran las siguientes: "Se oponen a leyes y prácticas gubernamentales injustas, comparten información y sensibilizan, prestan servicios fundamentales a personas en entornos complejos, cuestionan la opinión pública discriminatoria y se interfieren en intereses poderosos" (Amnistía Internacional, 2017, p. 8).

Según la Front Line Defenders (citado en Toro, 2016), desde 2014, Colombia encabeza la lista de los países donde son asesinados defensores de los derechos humanos. De acuerdo a la organización Somos defensores (2018) entre 2009-2017 se asesinaron 532 defensores.Respecto al número de asesinados en Colombia en el año 2017 la OACNUDH (2018) registró 121,

incluyendo a 84 defensores de los derechos humanos que ejercían liderazgo, 23 miembros de movimientos sociales y políticos y 14 personas muertas durante las protestas sociales. La OACNUDH también registró 41 intentos de asesinato; 213 amenazas; 61 violaciones de los derechos a la intimidad y la propiedad (entre ellas la toma no solicitada de fotografías y el robo de información); cuatro desapariciones forzadas; y la violación sexual de una mujer activista (p. 3). 
Entre las razones la OACNUDH (citado en Reinoso y Alvarado, 2018) señalo que "varias víctimas fueron asesinadas por apoyar las políticas derivadas del acuerdo (de paz), como la sustitución de cultivos ilícitos y la reforma rural integral" (párr. 8).

En la Tabla 1, se presentan los datos más significativos reportados por la OACNUDH (2018), evidenciando como la gran mayoría de defensores asesinados son hombres, sacrificados en zonas rurales (Antioquia y Cauca), y han sido cometidos por miembros de grupos armados, paramilitares, exguerrilleros y fuerza pública, y en menor medida por personajes que no hacen parte de ellas.

TABLA 1.

Datos sobre defensores de derechos humanos asesinados en Colombia en 2017

\begin{tabular}{|c|c|c|c|c|c|c|c|c|c|c|c|c|}
\hline \multirow{2}{*}{ Año } & \multirow{2}{*}{$\begin{array}{l}\text { Cantidad } \\
\text { de } \\
\text { asesinatos }\end{array}$} & \multicolumn{2}{|c|}{$\begin{array}{l}\text { Distribución por } \\
\text { genero }\end{array}$} & \multicolumn{2}{|c|}{$\begin{array}{c}\text { Condicion } \\
\text { sexual }\end{array}$} & \multicolumn{2}{|c|}{$\begin{array}{l}\text { Zonas de } \\
\text { ocurrencia }\end{array}$} & \multicolumn{5}{|c|}{ Autores } \\
\hline & & Hombres & Mujeres & Hetero & Lgbti & Rural & Urbana & $\mathrm{P}$ & $\mathrm{G}$ & $\mathrm{Sa}$ & $\mathrm{Fa}$ & $\mathrm{Sd}$ \\
\hline 2017 & 121 & 107 & 14 & 118 & 3 & 75 & 46 & 54 & 8 & 19 & 3 & 37 \\
\hline
\end{tabular}

Códigos: $P=$ Paramilitares. $G=$ Guerrilleros o exguerrilleros.

$S A=$ Sin afiliación a grupos. FA = Fuerzas Armadas. $S D=$ Sin datos .

Fuente: OACNUDH, 2018.

El contexto en el cual ocurrieron la mayoría de asesinatos, se caracteriza por la presencia de economías ilícitas, alta tasa de homicidios y de pobreza. Situación que lleva a suponer la escasa presencia del Estado en estas regiones (OACNUDH, 2018). Además de los elementos anteriores, Delgado (2017) manifiesta los altos niveles de militarización presentes y se está "desarrollando desde el 1 de enero de 2017 el "Plan Victoria, por la consolidación y estabilización de las regiones" (Plan Victoria) y se proyecta la puesta en marcha del Plan Orus o Plan Victoria Plus" (p. 5).

La sistematicidad de los asesinatos no ha sido aceptada plenamente por el gobierno nacional, todavía se escucha la desa- 
fortunada aseveración del Exministro de Defensa del Gobierno de Santos Luis Carlos Villegas, el 16 de diciembre de 2017 en una entrevista registrada en un noticiero en televisión nacional, donde aseveraba que la mayoría de los asesinatos de líderes sociales en las regiones "son frutos de un tema de linderos, de un tema de faldas, de peleas por rentas ilícitas" (NoticiasUnoColombia, 2017).

En contra de las opiniones de dirigentes gubernamentales, Delgado (2017) presenta los siguientes elementos que evidencian la sistematicidad:

1. Temporalidad. Los hechos muestran que durante el 2016 se presentaron 114 asesinatos y en el 2017 la cantidad ascendió a 167.

2. Distribución Geográfica de los Hechos. En 26 de los 32 departamentos han sido asesinados líderes sociales y defensores de derechos humanos.

3. Tipos de Liderazgo. Todos los asesinados tenían en común que defendían los derechos de las personas.

4. Modo de cometer homicidios. La mayoría de asesinatos son cometidos por sicarios.

5. Presuntos Responsables. No se conoce acerca de los autores intelectuales, la mayoría han sido cometidos por miembros de los grupos paramilitares.

6. Fines. Lo que se busca con estos asesinatos es tener el control territorial y de la población.

A pesar de las evidencias, el gobierno colombiano ha sido renuente a aceptar la sistematicidad. Según el Fiscal Néstor Humberto Martínez Neira, en una audiencia de "crímenes contra la paz" llevada a cabo en el Congreso en 2016: "Por el momento no hay una sistematicidad en las afectaciones...hay una multicausalidad en el origen de las amenazas, de los asesinatos y de las afectaciones a la integridad de estos líderes sociales" (Fiscalía General de la Nación, 2016). 
Los continuos crímenes contra los defensores de derechos humanos y la persistencia por parte del gobierno colombiano en negar su sistematicidad, han llevado a diversas organizaciones sociales a denunciar este caso ante organismos defensores de derechos humanos. Por este motivo La Comisión Interamericana de Derechos Humanos (CIDH) convocó a una audiencia el martes 21 de marzo de 2017 con 13 organizaciones de la sociedad civil que presentaron su versión de los hechos:

la situación de los defensores, defensoras, líderes y lideresas y las amenazas que enfrentan, la falta de garantías de no repetición en los crímenes contra integrantes de organizaciones sociales, y la denuncia de la búsqueda de mecanismos de impunidad para agentes estatales en el marco de las negociaciones de paz, a través de la Justicia Especial de Paz (Chato, 2017).

Ante las continuas afirmaciones de sistematicidad en los crímenes por parte de las organizaciones de la sociedad civil en dicha audiencia, la vice-fiscal Paulina Rivero manifestó que no es el momento para hablar de sistematicidad y que se pronunciaran cuando haya datos (Chato, 2017).

De acuerdo con los datos, parece que el momento empezó a formarse el 18 de diciembre de 2017, cuando el Fiscal, según El Espectador (citado en Bustillo, 2018) afirmó, "estamos identificando unos fenómenos que son preocupantes desde el punto de eventual presencia de reductos de autodefensas, que estarían actuando con algún grado de sistematicidad en algunas regiones del país" (p. 5).

En cuanto a la Procuraduría General de la Nación (2018):

El ministerio público insiste en que el conjunto de homicidios de líderes no es una sumatoria de crímenes aislados ni se trata de prácticas que se acumulan o suceden de manera casual o accidental. Especialmente, respecto de las violaciones de los derechos DDT como categoría específica, la Procuraduría encuentra que existe sistematicidad (p. 18). 
La aceptación de la sistematicidad es muy importante, ya que sin ello no es posible generar políticas que permitan cambios, según la Procuraduría General de la Nación (2018) "esta es una condición ineludible para el Estado, si decide enfrentar eficazmente y de forma articulada la crisis de seguridad de los DDT" (p. 83).

Los elementos anteriores que muestran las grandes dificultades y zozobra en que viven los defensores de los derechos humanos en Colombia, lleva a preguntarse,

¿quién defiende a los defensores de derechos humanos en Colombia?

En términos generales los Estados tienen la obligación de proteger sus ciudadanos y no ciudadanos de la violación de sus derechos humanos. Ellos deben garantizarles la preservación de los derechos a la vida, la salud y la libre expresión, la propiedad y otros más. De acuerdo con Chipoco (1992), quien tiene la obligación de proteger a las personas es el Estado, para el caso Colombia, pero ahí no termina la protección, porque otras naciones y la comunidad internacional tienen la obligación y el derecho de vigilar por el cumplimiento de dicho compromiso, ya que esta responsabilidad, de acuerdo con Maraniello (2013), es producto del cumplimiento de diferentes acuerdos, tanto nacionales (Constitucional) o internacionales (Tratados) que han firmado libre y autónomamente.

Bajo la consideración que toda nación tiene la obligación de proteger a sus ciudadanos y no ciudadanos y para ello cuenta con la legislación correspondiente, un defensor en riesgo solicitó a las autoridades competentes protección. La Corte Constitucional Colombiana, luego de analizar la difícil situación en que se encontraban él solicitante y todos los defensores, manifestada en la cantidad de asesinados, que muestran la realidad del riesgo, en la Sentencia T-590 (1998) declaró: 
que hay un estado de cosas inconstitucional en la falta de protección a los defensores de derechos humanos y, en consecuencia, hacer un llamado a prevención a todas las autoridades de la República para que cese tal situación, y, solicitar al Procurador General de la Nación y al Defensor del Pueblo que dentro de la obligación constitucional de guardar, proteger y promover los derechos humanos se le dé un especial favorecimiento a la protección de la vida de los defensores de los derechos humanos (p.39)

El Estado de Cosas Inconstitucional, resultó de la Sentencia SU-559 (1997), en la cual la Corte Constitucional, como "guardiana de la integridad de la constitución y de la efectividad de sus mandatos", insta a las diversas autoridades a actuar de manera mancomunada y cumplir sus obligaciones constitucionales, de forma tal que no se vulneren los derechos fundamentales de las personas.

Como logro concreto de esta decisión, en materia legislativa y en política publica quedó la "Política de promoción, respeto y garantía de derechos humanos y aplicación del derecho internacional humanitario", en la cual el Gobierno considera a los defensores como elementos fundamentales en la consolidación de la democracia:

El Gobierno considera que los grupos y asociaciones de la sociedad civil que trabajan en la promoción, protección y respeto de los derechos humanos y del derecho internacional humanitario, así como en la prevención y el esclarecimiento de las violaciones e infracciones de los mismos, constituyen un elemento indispensable de la democracia y contribuyen a la lucha contra la impunidad y a la prevención y reducción de los padecimientos de las víctimas (Ministerio de Defensa Nacional, 1998, p. $11)$.

Después de reconocer la situación que vivían los defensores en ese entonces, el Ministerio de Defensa Nacional (1998) se compromete a: 
atender integralmente la labor de los defensores de derechos humanos, el Gobierno continuará realizando esfuerzos dirigidos a combatir las causas estructurales que la afectan: el conflicto interno armado y el fenómeno de los grupos de autodefensa. Igualmente seguirá adelantando acciones para atender situaciones de riesgo (p. 11).

Desafortunadamente para los defensores, estas políticas no han tenido efectos. El Estado promulga Leyes, Acuerdos, Decretos, Directivas, como la Directiva 09 (2003), en la cual el Ministerio de Defensa Nacional traza políticas en materia de protección de los derechos humanos de Defensores de Derechos Humanos (Ministerio de Defensa Nacional, 2003), pero a pesar de esto, los asesinatos continúan, por ello, los defensores se vieron en la necesidad de acudir a organismos internacionales, amparados en la consideración que las violaciones de los derechos humanos desbordan las políticas internas, por tanto si sus derechos no son protegidos por el Estado de Derecho es necesario solicitar tal protección a organismos internacionales que hacen parte del sistema de protección universal de los derechos humanos (Bregaglio, 2008).

Avalan esas denuncias varios acuerdos firmados por Colombia, entre los cuales es de particular importancia resaltar el correspondiente al 9 de diciembre de 1998, dado a conocer por la OACNUDH (2003):

La Asamblea General de las Naciones Unidas aprobó la Declaración sobre el derecho y el deber de los individuos, los grupos y las instituciones de promover y proteger los derechos humanos y las libertades fundamentales universalmente reconocidos. Ella destaca que la responsabilidad primordial y el deber de promover y proteger los derechos humanos y las libertades fundamentales incumben al Estado. También reconoce el derecho y el deber de los individuos, los grupos y las instituciones de promover el respeto y el conocimiento de estos derechos y libertades en el plano nacional e internacional. 
Entre los derechos y deberes de esta Declaración se encuentra el siguiente: El derecho a la protección del Estado frente a toda violencia, amenaza, represalia, discriminación, negativa de hecho o de derecho, presión o cualquier otra acción arbitraria que afecte el ejercicio legítimo de sus derechos (OACNUDH, 2003).

En vista del continuo y creciente número de defensores asesinados en Colombia en los últimos años, y las denuncias de defensores colombianos en riesgo, la Comisión Interamericana de Derechos Humanos (CIDH) urgió a las autoridades competentes a trazar políticas que garantizaran la vida a los defensores e instó a protegerlos y a investigar los hechos, mediante la siguiente afirmación, «estas medidas de investigación y protección hacia las personas defensoras de derechos humanos sean abordadas desde una perspectiva integral y coordinada" y dictó medidas cautelares, las cuales según Martínez (2013, p. 5), "se convierte en prueba sustentatoria de la condición de vulnerabilidad en la que se encuentran los defensores de derechos humanos".

El Alto Comisionado de las Naciones Unidas (2018) ha expresado continuamente su preocupación por los asesinatos:

en vista de ello el Alto Comisionado de las Naciones Unidas para los Derechos Humanos llamó la atención por la descalificación, hostigamiento y señalamiento que han sido víctima los defensores de derechos humanos. Para combatir estas prácticas solicita a los funcionarios públicos acatar la Directiva 002 de la Procuraduría General de la Nación del 14 de junio de 2017.

Entre los pedidos, resalta el siguiente (OACNUDH, 2018):

Adoptar medidas para contribuir a la protección efectiva de los derechos de los defensores y defensoras de los derechos humanos y a sus organizaciones, integrantes de los movimientos sociales y políticos, así como la victimización a las que han sido expuestos. Advierte, igualmente, que es necesario definir e implementar medidas más efectivas para prevenir acciones similares, así como realizar las investigaciones y proferir las sanciones oportunas e idóneas cuando se presenten actos que afecten el ejercicio de su labor. 
Pero el Alto Comisionado de las Naciones Unidas, no tuvo en cuenta que los pedidos de la Procuraduría que generan responsabilidad inmediata de los funcionarios, no fueron tenidos en cuenta ya que después de ser promulgada la Directiva, fueron asesinados más de 100 defensores, según el registro efectuado por el Sistema de Información sobre Agresiones contra Defensores y Defensoras de Derechos Humanos -SIADDHH- del Programa No Gubernamental de Protección a defensores y defensoras de derechos humanos (Somos Defensores, 2018b), 77 de ellos entre enero-junio de 2018. En cuanto a los responsables de estos 77 homicidios, 59 son de autores desconocidos, seis la Fuerza Pública, tres los habrían cometido paramilitares, cinco disidencias de las desmovilizadas FARC y cuatro el ELN.

Como se puede notar los asesinatos continúan, pero ello no ha llevado a los defensores a bajar los brazos, tan es así que un grupo de defensores, de líderes sociales y ONGs se presentaron en los primeros días de mayo de 2018 en el Consejo de Derechos Humanos de Naciones Unidas en Ginebra y en la Corte Penal Internacional en La Haya dieron a conocer en el Informe conjunto de las organizaciones de derechos humanos colombianas para el Examen Periódico Universal de Colombia (Acción Colectiva de Objetores y Objetoras de Conciencia, et al, 2018), en el cual se detalla la difícil situación que atraviesan los derechos humanos en el país. Las críticas más fuertes fueron dirigidas a la fiscalía, la cual consideran inoperante y respeto a su accionar, manifestaron que dicha institución:

Carece de una estrategia de investigación que reconozca la existencia de paramilitares, la sistematicidad en los ataques, la condición de defensor(a) como móvil de las agresiones, la periodicidad y antecedentes de los ataques y la permanencia de actividades ilegales de inteligencia en su contra (2018 p. 31).

Las razones que llevaron a que estas organizaciones presentaran ante este organismo internacional tales denuncias, fueron 
dadas a conocer por el abogado Luis Guillermo Pérez, miembro del Colectivo de Abogados José Alvear Restrepo (citado en Verdad Abierta, 2018): "El asesinato, la persecución y las amenazas contra defensores de derechos humanos y líderes sociales no son prevenidos en Colombia; los determinadores de dichos crímenes no se buscan por tanto no son sancionados; no se reconoce que son crímenes de lesa humanidad ni su sistematicidad; no se busca los beneficiarios de dichos asesinatos".

En vista de la desprotección por parte del Estado, los defensores han creado diversos programas con la intención de crearles a los defensores un ambiente seguro para que puedan ejercer su liderazgo.

Entre esos programas se encuentra el diseñado por los integrantes de Somos Defensores (2010), quienes elaboraron un manual de protección que llamaron Un canto para persistir. El programa consta de cinco capítulos. El primero capítulo se titula Nuestro canto y en el presentan estrategias de prevención y protección. Para la prevención presentan cuatro momentos:

Primero: identificar el riesgo

Segundo: probabilidades de que se concrete el riesgo;

Tercero: respuestas propias e institucionales para disminuir un riesgo o los impactos de éste (reducir amenazas y vulnerabilidades y aumentar capacidades).

Cuarto: Diseñar un Plan de autoprotección y protección. (Prácticas individuales; Prácticas colectivas; Mecanismos institucionales; Protocolos para acciones específicas; un Ciclo de emergencia para riesgos especiales) (2010, p. 21).

En cuanto a prevención apoya a los defensores que se encuentran en zona de riesgo para que salgan de ella y les ayuda a conseguir donde ubicarse; brinda atención psicosocial a los defensores y sus familias para que manejen la ansiedad y el miedo; promueven la adopción de medidas políticas y respuestas de protección a los defensores y visibiliza la labor de los defensores, y eleva el costo político de una potencial agresión. 
Aunque este es un esfuerzo de grupos de defensores para prevenir ataques, quien debe generar programas y velar por su éxito es el Estado, que tiene la responsabilidad de proteger a los ciudadanos, pero sus programas han fracasado, las posibles razones de dicho fracaso son múltiples, la Oficina Internacional de los Derechos Humanos, Acción Colombia (2011), considera que ello puede estar relacionado con situaciones como las siguientes,

el excesivo tiempo que transcurre entre una solicitud de protección, una respuesta eficaz al defensor de parte de las autoridades y la aplicación de medidas de protección, en caso de ser aprobadas. Las medidas de protección también carecen de especificidad. Las defensoras y sus comunidades necesitan apoyo y protección diferenciales con medidas necesariamente consultadas y urgentemente implementadas, de conformidad con los mecanismos de protección nacional e internacional existentes (p. 4).

Para el Alto Comisionado de las Naciones Unidas para los derechos humanos Todd Howland (2017), la mejor herramienta para prevenir más asesinatos es la implementación del acuerdo de paz, para ello

La sociedad colombiana en su conjunto necesita involucrarse en el proceso de paz. Todas las iglesias y grupos religiosos, las instituciones académicas, las cooperativas, los sindicatos, el sector privado y otras entidades cívicas, al igual que la cooperación internacional deberían asociarse con veredas y corregimientos, que se encuentran en una situación de vulnerabilidad provocada por grupos ilegales, y ayudarles a lograr su inclusión social, política y económica (párr. 2).

\section{Conclusiones}

Lo descrito permite evidenciar la situación crítica que viven los defensores de derechos humanos en Colombia y como no ha habido forma de detener los crímenes que se cometen contra 
ellos, a pesar de las órdenes dadas por diversas organizaciones nacionales o internacionales, para que el Estado les brinde la protección debida.

Ante estas circunstancias es necesario ir más allá de las expresiones de apoyo masivas por parte de la población colombiana, tampoco se debe dejar la defensa de los defensores en ellos mismos, pues a pesar de sus programas de protección, se ha notado que es poco lo que pueden hacer para parar los asesinos,

Es indispensable exigir al gobierno mayor compromiso, para ello parte de sus miembros deben abandonar la persistencia en negar la sistematicidad de los asesinatos de defensores, ya que ello va en contra de su seguridad, en la medida que impide trazar estrategias de prevención y control de las acciones de los grupos que atentan contra ellos.

No hay que dejar de considerar que la mejor estrategia para la prevención de los asesinatos de los defensores sería la implementación del acuerdo de paz.

\section{REFERENCIAS}

Acción Colectiva de Objetores y Objetoras de Conciencia, et al (2017). Informe conjunto de las organizaciones de derechos humanos colombianas para el Examen Periódico Universal de Colombia. Bogotá, D.C.: ARFO. [Online]. Recuperado de https://stats.karisma.org.co/wp-content/uploads/2018/04/Informe-de-derechos-humanosy-derecho-humanitario-en-Colombia-2013-2017.pdf

Amnistía Internacional. (2017). Ataques letales pero prevenibles asesinatos y desapariciones forzadas de quienes defienden los derechos humanos. London: Amnesty International Ltd.

Bregaglio, R. (2008). Sistema Universal de Protección de Derechos Humanos. Lima: Pontificia Universidad Católica del Perú. 
Bustillo, J. (2018). Panorama de la situación de defensores y defensoras de los derechos territoriales en la región Caribe. Bogotá, D.C.: CINEP.

Chato, P. (marzo 11, 2017). Colombia. El Gobierno vuelve a negar la realidad ante la CIDH. Resumen Latinoamericano. [Online]. Recuperado de http://www.resumenlatinoamericano.org/2017/03/22/colombia-el-gobierno-vuelve-a-negar-la-realidad-ante-la-cidh/

Chipoco, C. (1992). La protección universal de los derechos humanos una aproximación critica. San José: Instituto Interamericano de Derechos Humanos.

Delgado, C. (2017). Factores que evidencian sistematicidad en el asesinato de lideres/as sociales y defensores/ as de Derechos Humanos en Colombia. [Online]. Recuperado de http://www.indepaz.org.co/wp-content/ uploads/2017/12/Factores-que-evidencian-sistematicidad-en-el-asesinato-de-1\%C3\%ADderesas-socialesy-defensoresas-de-Derechos-Humanos-en-Colombia. pdf

Encinas, C. (2018). Necesidad de crear un mecanismo nacional de protección especial para defensores y defensoras de derechos humanos en Bolivia. [Tesis Magistral]. Universidad Andina Simón Bolívar, La Paz, Bolivia.

Front Line Defenders (2018). Basta de asesinatos. Ireland: Front Line Defenders.

Gutiérrez, J. (2014). Costos sociales de transacción de la Ley de Restitución de Tierras en Colombia: Un país sin Reforma Agraria. Jurídicas CUC, 10(1), 157-196.

Howland, T. (junio 30, 2017). Cómo prevenir el asesinato de defensores de derechos humanos. Semana. [Online]. Recuperado de https://www.semana.com/opinion/articulo/prevenir-el-asesinato-de-defensores-de-derechos-humanos/530592 
Human Rights First. (2009). Los defensores de derechos humanos acusados sin fundamento. Presos y señalados en Colombia. New York: Human Rights First. Recuperado de https://www.humanrightsfirst.org/wp-content/ uploads/pdf/090211-HRD-colombia-esp.pdf

Maraniello, P. (2013). Los derechos humanos y la responsabilidad del Estado. Criterio Jurídico Santiago de Cali, 13(2), 127-148.

Martínez, J. (2003). La desprotección de los defensores de Derechos Humanos en Colombia, en perspectiva constitucional durante los años 1992-2012. [Tesis pregrado]. Universidad Jorge Tadeo Lozano, Bogotá, D.C., Colombia. Recuperado de www.utadeo.edu.co/files/collections/documents/field_attached_file/007-2013_jonathan_karlo_martinez_ojeda_asistencia_de_investigacion_0.pdf Noticias Uno. (diciembre 16, 2017). El ministro de Defensa dice que a los líderes sociales los matan por líos de faldas y de vecinos. NoticiasUnoColombia. [Video Youtube]. Recuperado de https://canal1.com.co/noticias/los-matan-por-borrachos-mindefensa/

ONU. OACNUDH. (2018). Informe anual del Alto Comisionado de las Naciones Unidas para los Derechos Humanos sobre la situación de los derechos humanos en Colombia. [Online]. Recuperado de https://www.hchr.org.co/ index.php/informes-y-documentos/informes-anuales

ONU. OACNUDH. (2004). Los Defensores de los Derechos Humanos: Protección del Derecho a Defender los Derechos Humanos. [Online]. Recuperado de https://www.ohchr. org/Documents/Publications/FactSheet29sp.pdf

ONU. OACNUDH. (2003). La Importancia de la Protección y Defensa de los Defensores de los Derechos Humanos. [Online]. Recuperado de https://www.hchr.org.co/index.php/informacion-publica/comunicados-de-prensa/ ano-2003/491-blank-sp-1347 
Oficina Internacional de los Derechos Humanos. Acción Colombia (2011). Colombia. Defensores de Derechos Humanos bajo amenaza. [Online]. Recuperado de http:// www.oidhaco.org/uploaded/content/article/544809907. pdf

Reinoso, G. y Alvarado, A. (abril 18, 2018). Desde el 2016 han asesinado a 164 defensores de derechos humanos. $E l$ Tiempo. [Online]. Recuperado de http://www.eltiempo. com/justicia/investigacion/defensores-de-derechos-humanos-asesinados-en-colombia-206282

Rehm, L. (2014). La construcción de las subculturas políticas en Colombia: los partidos tradicionales como antípodas políticas durante La Violencia, 1946-1964. Historia y Sociedad, 27(1).17-48.

República de Colombia. Centro de Memoria Histórica. (2013). ¡Basta ya! Colombia: memorias de guerra y dignidad. Resumen. Bogotá, D.C.: Pro-Off Set.

República de Colombia. Corte Constitucional. (20 de octubre de 1998). Exp. T-174150 [Sentencia T-590]. MP: Alejandro Martinez Caballero. Recuperada de http://www.corteconstitucional.gov.co/relatoria/1998/T-590-98.htm

República de Colombia. Corte Constitucional. (de 1997). Exp. acumulados T-115839 y T-116052. [Sentencia SU-559]. MP: Eduardo Cifuentes Muñoz. Recuperada de http:// www.corteconstitucional.gov.co/relatoria/1997/SU55997.htm

República de Colombia. Fiscalía General de la Nación. (2016). "No hay una sistematicidad hasta el momento en las afectaciones a la integridad de los lideres sociales": Fiscal General de la Nación. [Online]. Recuperado de https://www.fiscalia.gov.co/colombia/noticias/no-hayuna-sistematicidad-hasta-el-momento-en-las-afectaciones-a-la-integridad-de-los-lideres-sociales-fiscal-general-de-la-nacion-2/ 
República de Colombia. Ministerio de Defensa Nacional. (2003). Directiva número 009 del Ministerio de Defensa Nacional. [Online]. Recuperado de http://historico. derechoshumanos.gov.co/Programa/Documents/2010/ legislacion/Directiva009de2003-Mindefensa.pdf

República de Colombia. Ministerio de Defensa Nacional. (1998). Políticas de promoción, respeto y garantía de los derechos humanos y de aplicación del derecho internacional humanitario. [Online]. Recuperado de https:// www.mindefensa.gov.co/irj/go/km/docs/Mindefensa/ Documentos/descargas/Asuntos_de_Interes/Derechos_Humanos/politica_promocion_dh_dih.pdf

República de Colombia. Procuraduría General de la Nación (2018). Violencia sistemática contra defensores de derechos territoriales en Colombia. Bogotá, D.C.: Instituto de Estudios del Ministerio Público.

Somos defensores (2018). Piedra en el zapato. Bogotá, D.C.: Inversiones CIMAZ.

Somos defensores (2018b). Más allá de las cifras. Segunda parte. Bogotá, D.C.: : Inversiones CIMAZ.

Somos defensores (2010). Un canto para persistir. Bogotá, D.C.: Alta Voz Ediciones.

Toro, J. (enero 15, 2016). Colombia es el país donde matan más defensores de DDHH. Pacifista. [Online]. Recuperado de http://pacifista.co/colombia-es-el-pais-donde-matanmas-defensores-de-ddhh/

Verdad Abierta (mayo 11, 2018). Tragedia de líderes sociales en Colombia toca las puertas en Europa. Verdad Abierta. [Online]. Recuperado de https://verdadabierta.com/ tragedia-lideres-sociales-colombia-toca-las-puertaseuropa/ 
Camila Villamizar-Acosta es Magister (en formación) en promoción y protección de los derechos humanos de la Universidad del Magdalena (Colombia). Historiadora y Archivista. Universidad Industrial de Santander (Colombia). Especialista en Derechos humanos y derecho internacional humanitario (Universidad del Magdalena, Colombia). http://orcid.org/00000002-3812-9745 